\title{
FUNDAMENTAÇÃO ÉTICA DO DESENVOLVIMENTO SUSTENTÁVEL EM KANT, HABERMAS E HANS JONAS
}

\author{
ETHICAL FOUNDATION OF THE SUSTAINABLE DEVELOPMENT \\ IN KANT, HABERMAS AND HANS JONAS
}

\author{
Sérgio Xavier de Camargo ${ }^{1}$ \\ Ana Cláudia Duarte Pinheiro ${ }^{2}$
}

\begin{abstract}
RESUMO: A possibilidade de desenvolvimento econômico associado à preservação ambiental é questão relevante para as sociedades contemporâneas. O desenvolvimento sustentável fundamenta-se em questões de conteúdo ético que transcendem aspectos legais, econômicos e políticos. É objetivo deste artigo investigar, em Immanuel Kant, Jürgen Habermas e Hans Jonas, as bases éticas justificadoras do desenvolvimento sustentável. Em Kant, o imperativo categórico, a valorização da universalidade das ações, e a compreensão dos seres e da natureza como fins em si; ainda, as condições para a paz, requisitos para a cidadania cosmopolita, e sua conseqüência inequívoca: a sustentabilidade. O agir comunicativo de Habermas, ocupado com a justiça, mostra a possibilidade de escolhas moralmente adequadas porque compartilhadas pelo interesse comum, e sua ética do discurso, onde todos têm a mesma possibilidade e legitimidade de participar do estabelecimento de normas que vinculem a todos. A sustentabilidade contempla os princípios da informação e o da participação, princípios do Direito Ambiental, afinados à ética do discurso. E o princípio da Responsabilidade de Jonas, que aponta o descompasso entre a factibilidade da destruição, inclusive ambiental, e a consciência ética das conseqüências imprevisíveis dos atos praticados no presente. Apoiando-se na possibilidade de danos, preocupa-se em evitar que as possibilidades técnicas e práticas levem os homens irresponsavelmente para além dos limites da viabilidade da vida. A sustentabilidade, acorde o princípio de responsabilidade, clama do homem por uma ação de tutela do meio ambiente, elemento vulnerável frente à capacidade de destruição desse mesmo homem. As contribuições das éticas de Kant, Habermas e Jonas podem auxiliar na identificação das variáveis implícitas em toda deliberação ética/moral, sustentando decisões mais condizentes com os requisitos do desenvolvimento sustentável, permitindo assim a perpetuação da vida, em todas as suas surpreendentes dimensões e possibilidades.
\end{abstract}

Palavra-chave: Ética; Meio ambiente; Desenvolvimento sustentável; Kant; Habermas; Hans Jonas.

1 Graduado em Odontologia (UEL), mestre em Saúde Coletiva (UEL); especialista em Odontopediatria (AONP), em Saúde Coletiva (UEL), em Bioética (UEL), e em Filosofia Moderna e Contemporânea (UEL); docente dos cursos de Medicina e Enfermagem (UEL); graduando em Direito (UEL). Londrina, PR.

2 Graduada em Direito e em Serviço Social (UEL), mestre em Direito Negocial (UEL); especialista em Direito Empresarial (UEL), em Direito Tributário (IBET), e em Administração e Marketing (UEL); docente dos cursos de graduação e pós-graduação em Direito (UEL e UNIFIL). Londrina, PR. 


\begin{abstract}
The possibility of economic development associated with environmental preservation is a relevant question to the contemporary societies. The sustainable development is based on issues of ethical content that transcend legal, economic and political matters. The aim of this paper is to investigate, in Immanuel Kant, Jürgen Habermas and Hans Jonas, the ethical bases that justify the sustainable development. In Kant, the categorical imperative, the appreciation of the universality of actions, and understanding of human beings and nature as ends in themselves, yet, the conditions for peace, conditions for cosmopolitan citizenship, and its unequivocal result: the sustainability. The communicative action of Habermas, engaged with justice, shows the possibility of morally appropriate choice because it shared the common interest, and his discourse ethics, which all have the same possibility and legitimacy to participate in setting standards that bind all. The sustainability includes the principles of information and participation, principles of environmental law, akin to discourse ethics. And the principle of responsibility of Jonas, that describes the gap between the feasibility of destruction, including environmental and ethical awareness of the unforeseen consequences of acts performed in the present. Relying on the possibility of damage, is concerned to ensure that the technical possibilities and practices leading men irresponsibly beyond the limits of viability of life. Sustainability, in accordance with the principle of responsibility, the man cries out for an action for guardianship of the environment, vulnerable front element to the destructiveness of that man. The contributions of ethics of Kant, Habermas and Jonas can help in identify the variables implied in any ethical / moral deliberation, supporting decisions more consistent with the requirements of sustainable development, thus allowing the perpetuation of life in all its amazing dimensions and possibilities.
\end{abstract}

Palavras-Chave: Ethical environment; Sustainable development; Kant; Habermas; Hans Jonas.

\title{
INTRODUÇÃO
}

A possibilidade de desenvolvimento econômico associado à preservação ambiental é questão emergente e relevante para as sociedades contemporâneas. O desenvolvimento sustentável fundamenta-se em questões de conteúdo ético que desafiam e transcendem aspectos legais, econômicos e políticos. É objetivo deste artigo investigar, em Emmanuel Kant, Jürgen Habermas e Hans Jonas, as bases éticas que justificam o conceito de desenvolvimento sustentável.

A idéia do desenvolvimento sustentável tem irrompido com força em nossa sociedade, ainda que, infelizmente, não tenha propiciado praticamente quase nada de suas virtualidades, pois é difícil que a humanidade possa transitar até o futuro sem que este projeto se realize, mesmo que paulatinamente (MATEO, 2003; tradução nossa). 
Na década de 1980, os cientistas chamam a atenção para problemas como: aquecimento global, destruição da camada de ozônio, chuva ácida, e a desertificação. É nesse cenário que surge a Comissão de Brundtland, formalmente batizada de Comissão Mundial sobre Meio Ambiente e Desenvolvimento, criada pela ONU, em 1983. Desejava-se criar uma agenda global com objetivo de capacitar a humanidade e deixá-la preparada para enfrentar os principais problemas ambientais do planeta e assegurar o progresso humano sem comprometer os recursos para as futuras gerações. Foi o relatório da Comissão Brundtland que pôs em circulação a expressão "desenvolvimento sustentável”. A Comissão Brundtland recomendou à Assembléia Geral da ONU que convocasse a II Conferência Internacional do Meio Ambiente e Desenvolvimento, marcada para 1992, que se realizou no Rio de Janeiro, conhecida como Rio 92, com a missão de estabelecer uma agenda de cooperação internacional, a agenda 21, para pôr em prática ao longo do século XXI o desenvolvimento sustentável do planeta (ALMEIDA, 2002).

O desenvolvimento sustentável pode ser conceituado como aquele que "satisfaz as necessidades do presente sem comprometer a capacidade de as futuras gerações satisfazerem suas próprias necessidades" (COMISSÃO MUNDIAL SOBRE MEIO AMBIENTE E DESENVOLVIMENTO, 1988).

Não obstante, não é essa a única definição aceita pelos especialistas e ainda não se pôde chegar a um consenso sobre o conteúdo e significado de desenvolvimento sustentável. O debate centra-se, fundamentalmente, sobre a idéia de crescimento econômico. Para os redatores do Informe Brundtland, o crescimento econômico é imprescindível para erradicar a pobreza; pobreza que por sua vez, ocasiona comportamento ambientalmente não sustentável. Para os críticos do conceito, o crescimento econômico gera entropia, que é a formulação energética da crise ambiental, e defendem um "desenvolvimento" que maximize os recursos existentes assim como a correta distribuição da riqueza, antes de optar por um maior crescimento econômico (TUR e GÓMEZ, 2002).

Para Almeida (2002), o atual modelo conceitual de mundo, fruto de uma visão cartesiana, mecanicista, forjada em 300 anos de Revolução Científica e Industrial acostumou-se em dividir o universo em compartimentos estanques para poder entendê-lo. Nos últimos anos do século XX o homem viu-se às voltas com a constatação de que a natureza não se deixa apreender completamente pelas ferramentas tradicionais de análise. Para ser compreendida, pede um novo paradigma: orgânico, holístico, integrador.

Segundo Hugo Ferraz Penteado, autor da obra "Ecoeconomia - Uma nova abordagem", a teoria econômica, independentemente de sua corrente, possui três mitos: a) o Mito 
Mecanicista: Os processos econômicos são explicados com as leis da mecânica e por essas leis o sistema econômico é considerado neutro para o meio ambiente. Todos os processos econômicos mecanicistas são reversíveis, previsíveis e incapazes de gerar mudanças qualitativas no sistema; b) o Mito Tecnológico: Embora a tecnologia dependa de outras ciências que não a Economia, os economistas utilizam os avanços tecnológicos para concluir que o meio ambiente é inesgotável; c) o Mito Neoliberal: Se os dois primeiros mitos tornam possível acreditar no crescimento eterno de estruturas materiais e populações, o terceiro mito justifica esse objetivo. Crescer por crescer não tem apelo algum, mas dizer que só o crescimento produz benesses sociais acaba justificando todas as tragédias que estamos produzindo.

Para Tur e Gómez (2002), poderíamos definir desenvolvimento como o projeto de mudança demográfica, econômica, social, política e cultural dos países do chamado "Terceiro Mundo", ou "em desenvolvimento". Iniciou-se no começo da década de cinqüenta e após cinco décadas de implementação, se constata o "fracasso" do projeto desenvolvimentista. Se bem que o mundo tem progredido em alguns aspectos (por exemplo, aumento da expectativa de vida e da alfabetização do conjunto da população mundial), as diferenças entre ricos e pobres se têm feito cada vez maiores. Quase dois terços da população mundial é declarada "estatisticamente pobre" e regiões inteiras (por exemplo, o Sahel) são consideradas “irrecuperáveis". Desafortunadamente, não parece que o processo de globalização mudará estas tendências, mas que, pelo contrário, pode potencializá-las. À pobreza e desigualdade haveria que se acrescentar o impacto ambiental da aplicação da ideologia e da tecnologia do desenvolvimento nos países do Terceiro Mundo. A dependência econômica e cultural, a industrialização sem internalização dos custos, a espoliação dos recursos naturais e a rápida e desequilibrada urbanização dos países em desenvolvimento - tudo isto impulsionado pelo desenvolvimento -, potencializam os problemas ambientais nestes países.

Dado que os resultados têm sido pouco satisfatórios, que aumentou a desigualdade sócio-econômica e que têm crescido os problemas ambientais desde o fim dos anos setenta, tem aparecido uma corrente fortemente crítica em relação ao conceito de desenvolvimento. Seguindo a W. Saches (apud TUR e GÓMEZ, 2002), podemos resumir as principais críticas ao conceito e prática do desenvolvimento nos seguintes pontos: 1) Unilinearidade teleológica e homogeneização cultural; 2) Racionalidade exclusivamente economicista; 3) Insustentabilidade ambiental do desenvolvimento.

Em outras palavras, o estado de desenvolvimento foi entendido como o fim da única evolução social possível que desembocaria num único modelo cultural para todo o mundo: a 
forma de vida ocidental. Esta forma de vida está regida pelo princípio da racionalidade econômica ao que se devem submeter todos os demais aspectos, inclusive a natureza, que se acaba no "altar" do progresso econômico produzido pela industrialização (TUCKER, apud TUR e GÓMEZ, 2002).

Tur e Gómez (2002) agrupam as críticas que tem recebido o conceito de desenvolvimento sustentável em duas: 1) aquelas que criticam a falta de radicalização do projeto em sua dimensão político-social; 2) aquelas que se centram no debate sobre desenvolvimento versus crescimento:

1) A falta de radicalização do projeto de desenvolvimento sustentável. Se acusa ao desenvolvimento sustentável de que seu objetivo último não é tanto a busca de um equilíbrio global entre o meio ambiente e economia como, na realidade, o manutenção da prosperidade dos paises industrializados. Desta forma, se conceitua o desenvolvimento sustentável como uma estratégia do centro encaminhada, fundamentalmente, a manter a ordem sócio-econômica vigente mediante concessões aos países em vias de desenvolvimento e ao movimento ambiental, e ligeiras transformações ao aparelho industrial mundial que reduza os riscos ambientais mais eminentes (JIMENEZ HERRERO), como um mecanismo para reduzir as ameaças aos sistemas, mas sem ter que transformar sua essência e sua estrutura, ambas com base na desigual distribuição do poder entre classes e paises.

2) $\mathrm{O}$ debate entre crescimento e desenvolvimento. (....) crescer significa aumentar de tamanho ao acrescentar outros materiais por assimilação ou acréscimo. $\mathrm{O}$ crescimento é um incremento quantitativo na escala física. Desenvolver é ampliar ou realizar as potencialidades de algo, levar gradualmente a um estado mais completo maior ou melhor. O desenvolvimento é uma melhora ou desdobrar qualitativo das potencialidades.

Nesse sentido, uma economia pode crescer sem desenvolvimento, ou desenvolver-se sem crescimento ou ter ambas as coisas ou nenhuma delas. Há muitos economistas e políticos que defendem a imperiosa necessidade de crescimento econômico como único meio de erradicar a pobreza do mundo sempre que se faça de forma sustentável. Afirmam que a dramática situação dos paises em desenvolvimento ou do Terceiro Mundo obriga a que aumentem seu PNB a fim de que possam satisfazer as necessidades básicas de suas populações. Ao entender que o crescimento econômico destas regiões não pode ser incompatível com a proteção do meio ambiente, se formula o conceito de crescimento econômico sustentável, que significa que o PNB real per capita aumenta no transcurso do tempo e que tal incremento não se vê ameaçado pela resposta dos impactos biofísicos (contaminação, problemas de recursos) ou impactos sociais 
(desorganização social) e que tampouco degrada a um bem emergente com é o meio ambiente (PEARCE, apud TUR e GÓMEZ, 2002).

\section{ÉTICA E MORAL}

Tendo-se por pressuposto deste estudo que a sustentabilidade é opção social e política de natureza ética, discutem-se sucintamente as varias formas de interpretação dos termos Ética e Moral. De acordo com Cortina e Matínez (2005), a Ética é entendida como parte da Filosofia que se dedica à reflexão moral, Ética como Filosofia Moral:

\footnotetext{
Como parte da Filosofia, a Ética é um tipo de saber que se tenta construir racionalmente, utilizando para tanto o rigor conceptual e os métodos de análise e explicação próprios da Filosofia. Como reflexão sobre as questões morais, a Ética pretende desdobrar conceitos e argumentos que permitam compreender a dimensão moral da pessoa humana nessa sua condição de dimensão moral.
}

Desde sua origem entre os filósofos da antiga Grécia, a Ética é um tipo de saber normativo, isto é, um saber que pretende orientar as ações dos seres humanos. A moral também é um saber que oferece orientações para a ação, mas enquanto ela propõe ações concretas em casos concretos, a Ética - como Filosofia moral - remonta à reflexão sobre as diferentes morais e as diferentes maneiras de justificar racionalmente a vida moral, de modo que sua maneira de orientar a ação é indireta: no máximo, pode indicar qual concepção moral é mais razoável para que, a partir dela, possamos orientar nossos comportamentos (CORTINA e MARTINEZ, 2005).

Frequentemente utiliza-se a palavra "ética" como sinônimo do que anteriormente chamamos de "a moral", ou seja, esse conjunto de princípios, normas, preceitos e valores que regem a vida dos povos e dos indivíduos. A palavra "ética" procede do grego ethos, que significa "morada", "lugar em que vivemos", mas posteriormente passou a significar "o caráter", o "modo de ser" que uma pessoa ou um grupo vai adquirindo ao longo da vida. Por sua vez, o termo "moral" procede do latim mos, moris, que originariamente significava "costume", mas em seguida passou a significar também “caráter" ou "modo de ser". Desse modo, "ética” e "moral" confluem etimologicamente em um significado quase idêntico: tudo aquilo que se refere ao modo de ser ou caráter adquirido como resultado de pôr em prática alguns costumes ou hábitos considerados bons. 


\section{KANT: IMPERATIVO CATEGÓRICO, DIREITO COSMOPOLITA E PAZ}

A Ética de Kant baseia-se formalmente na aplicação do imperativo categórico. Kant adverte que todo ato voluntário se apresenta à razão, à reflexão, na forma de um imperativo. $\mathrm{O}$ imperativo categórico é expresso por três formulações.

Em Kant (apud SOSOE, 2003) encontramos: “Age somente segundo a máxima graças à qual tu podes querer ao mesmo tempo que ela se torne uma lei universal". É a primeira formulação. O momento da universalidade da lei moral é determinado principalmente na fórmula do imperativo categórico, que pode ser considerada a tentativa de Kant de aplicar a teoria moral aos seres humanos. A aplicação é feita pela apresentação do tipo de lei universal. Para Kant, esse tipo corresponde à forma pela qual a natureza se faz conhecer. Nós não conhecemos a natureza senão segundo as suas leis naturais. A lei moral se apresenta então sob a forma da legalidade universal da natureza: “Age como se a máxima da tua ação devesse ser instituída em lei universal da natureza". A simples legalidade não sendo ainda o dever moral, Kant não se detém na apresentação do tipo ou da forma da lei. Para que haja o dever moral propriamente dito, ainda é preciso que o móbil seja o agir por dever ou por respeito à lei moral. Kant dá um mínimo de conteúdo e, portanto, de aplicação concreta ao ser humano.

Pela concepção kantiana, desenvolvimento sustentável seria possível pela aplicação da universalização das ações e medidas de ecoeficiência e responsabilidade social. O impacto global da preservação do meio ambiente depende do entendimento de que as ações locais e individuais tem impactos globais e coletivos. A deliberação individual sobre as ações deve abranger considerações quanto a sua viabilidade ou inviabilidade para a vida humana. O desenvolvimento sustentável funda-se na ética, visto que sua realização de forma universal beneficia a todos os habitantes do planeta.

Encontramos então em Kant, em seu imperativo categórico, o princípio do fim em si mesmo. "Age de tal maneira que uses a humanidade, tanto na tua pessoa como na pessoa de qualquer outro, sempre e simultaneamente como fim, e nunca simplesmente como meio" (KANT, 2003, p. 69).

Nesta segunda formulação do imperativo categórico, percebe-se a possibilidade da ação humana sobre a natureza e os recursos ambientais, e até mesmo sobre os próprios homens, objetivando sua utilização como simples meio, meio de acumulação financeira, meio de enriquecimento, ou usufruto privado dos bens ambientais e coletivos da humanidade, o que não seria justo, nem moral. 
O uso da Natureza como simples meio contrariaria o princípio do acesso eqüitativo dos recursos naturais, que prevê que: "Os bens que integram o meio ambiente planetário, como água, ar e o solo, devem satisfazer as necessidades comuns de todos os habitantes da Terra. (...) Desde que utilizável o meio ambiente, adequado pensar-se em meio ambiente como bem de uso comum do povo" (MACHADO, 2002).

Segundo Borges, Dall'agnol e Dutra (2002), a terceira fórmula do imperativo categórico, obtida a partir da concepção da vontade de um ser racional, compreendida como vontade autônoma, isto é, a que governa a si mesma, é considerada como o único fundamento possível da obrigação moral. O reconhecimento dessa vontade autolegisladora se expressa na fórmula da autonomia: "Age de forma tal que tua vontade possa fornecer a lei universal através de todas as suas máximas" (KANT, 2003). Essa terceira fórmula admite uma variação, pela qual a vontade autônoma é pensada como vontade legisladora de um reino dos fins, ou seja, de uma comunidade ideal de seres racionais: "Age de acordo com as máximas que orientam o legislador universal de um possível reino dos fins".

Assim, a possibilidade de realização do desenvolvimento sustentável teria como pressuposto a determinação livre e autônoma da vontade humana, individual ou coletiva, estabelecendo regras racionais de convívio coletivo, visando à instituição de um "reino dos fins", ou seja, alcançando a finalidade humana: uma sociedade fundamentada na razão e no dever, e por conseqüência, na ação ética.

Por outro lado, de acordo com Almeida (2002), a paz, a democracia e a estabilidade política seriam, entre outros, pré-requisitos do paradigma da sustentabilidade.

No texto "À Paz Perpétua", Kant avalia em profundidade os requisitos para a paz, e estende o imperativo categórico ao Direito Constitucional, ao Direito das Gentes e ao Direito Cosmopolita. Realiza para isso uma tripartição do Direito público, apresentando-o como postulado subjacente a todos os artigos definitivos, conforme nota do autor (KANT, 1995. p. 127):

Todos os homens que entre si podem exercer influências recíprocas devem pertencer a qualquer constituição civil. Mas toda constituição jurídica, no tocante às pessoas que nela estão, é

1. Uma constituição segundo o direito político (Staatbürgerrecht) dos homens num povo (ius civitatis);

2. Segundo o direito das gentes (Volkerrecht) dos Estados nas suas relações recíprocas (ius gentium);

3. Uma constituição segundo o direito cosmopolita (Weltbürgerrecht), enquanto importa considerar os homens e os Estados, na sua relação externa de influência recíproca, como cidadãos de um estado universal da humanidade (ius cosmopoliticum). 
Ao conceber a existência de um direito cosmopolita, Kant apresenta as bases para o entendimento da Terra como espaço coletivo da humanidade, independentemente das divisões geopolíticas dos estados nacionais (CAMARGO, 2006). Enquanto pertencentes à humanidade, os homens compartilham de problemas comuns, como os desafios do desenvolvimento sustentável, que influenciam a toda a humanidade. Configura-se assim uma nova cidadania, a cidadania cosmopolita, planetária, relativa aos deveres e direitos globais dos homens.

Em Kant, Estado de paz é o estado civil fundado na idéia a priori de um contrato social originário, mensurável a qualquer momento em seu estágio de aproximação a ela. Esse estado só se institui progressivamente na medida do reconhecimento dos direitos de cada indivíduo em uma sociedade organizada autonomamente. Isto é, a paz instaura-se e torna-se duradoura num estado de direito democrático. A instituição da paz emerge da pacificação interna em um Estado. Mas devido à necessária interdependência dos homens e Estados dentro de uma esfera limitada da Terra, ela só se perfaz mediante um direito internacional e um direito cosmopolita. A paz é coextesiva à idéia de uma humanidade civilizada (ROHDEN, 1997).

Para Cortina (1997), é necessário universalizar a cidadania social cosmopolita:

\footnotetext{
Nos últimos tempos tem se multiplicado os livros e congressos sobre Exclusão, e não seria demais perguntar antes de tudo - Exclusão de que? Os bens da Terra - esta seria a primeira afirmação - são bens sociais. (...) Os bens do universo são bens sociais. (...) distribuir os bens sociais a todas as pessoas, porque todas são donas de tais bens, é o primeiro e mais elementar princípio da justiça. (...) com isso não se fará senão lutar por mínimos de justiça que a cidadania social cosmopolita exige". A autora acrescenta: "poderíamos dizer, portanto, que o reconhecimento da cidadania social é condição sine qua non na construção de uma cidadania cosmopolita que, por ser justa, fará sentir-se e saber-se por todos os homens cidadãos do mundo" (tradução nossa).
}

\section{HABERMAS E O AGIR COMUNICATIVO}

Outros autores, porém, fazem maior distinção entre a Ética e a Moral. Habermas (1993) identifica três possibilidades de ação: o agir para fins, o agir ético e o agir moral. Os dois primeiros são considerados estratégicos, instrumentais, visando fins específicos, objetivos concretos, enquanto o terceiro é considerado um agir comunicativo, não instrumental.

"Tarefas práticas colocam-se da perspectiva de um agente que parte de suas metas e preferências. (...) No agir estratégico, os participantes supõem que cada um decide de maneira egocêntrica, segundo critério de seus próprios interesses". E acrescenta: “também as questões 
éticas não exigem ruptura completa com a perspectiva egocêntrica; elas se referem ao télos de minha vida. deste ponto de vista, outras pessoas, outras histórias de vida e esferas de interesse ganham significado apenas na medida em que estejam unidos ou entrelaçados à minha identidade e à minha história de vida (...)" (HABERMAS, 1993). Tradições e valores coletivos de grupos específicos, como os religiosos, também compõem esta categoria.

Quanto ao agir moral, Habermas assim o expressa: “Aproximamo-nos, com efeito, do modo de consideração moral assim que examinamos se nossas máximas são conciliáveis com as máximas dos outros. (...) Num caso se examina se uma máxima é boa para mim ou adequada à situação; no outro caso, se posso querer que uma máxima seja observada como lei universal para todos. Trata-se, lá, de uma reflexão ética; aqui, de uma reflexão moral (...)” (HABERMAS, 1993).

De acordo com sua intencionalidade, o agir poderia ser adequado a fins, do bom (ético) e do justo (moral). Para Habermas, o termo Ética representaria decisões sobre questões particulares, visando o benefício de grupos específicos. Diferentemente, o autor propõe a aplicação do termo Moral às deliberações sobre questões de interesse coletivo, cosmopolita, que considera um agir comunicativo. A questão ambiental do desenvolvimento sustentável enquadra-se no agir moral, comunicativo, por referir-se a questões de interesse coletivo da humanidade, bem como solicitando uma ação desinteressada, não pragmática, visando à justiça e ao bem comum.

Aplicando os conceitos de Habermas, a sustentabilidade pode ser compreendida como efeito de um agir necessariamente comunicativo, visando ao bem comum, acima das ações instrumentais, visando pragmaticamente a um fim concreto, e mesmo das ações estratégicas, visando ao bem de grupos específicos. O desenvolvimento sustentável requer atitudes morais que levem em conta a justiça para a coletividade, a equidade, a qualidade de vida para todos.

\section{HANS JONAS: O PRINCÍPIO DE RESPONSABILIDADE}

Para o filósofo alemão Hans Jonas, o progresso científico transformou a humanidade em uma espécie de "Prometeu irresistivelmente descontrolado", cuja já enorme capacidade de ação continua a aumentar e com sempre menos regras capazes de exercer um controle sobre ela. Ciência e tecnologia deram à razão um poder desmedido, mas fizeram isso numa condição de profundo "vazio ético", produzido pela própria razão moderna (MANCINI et al., 2000). O autor considera que o caminho para se percorrer deve ser, acima de tudo, aquele de adquirir a idéia dos efeitos a longo prazo do agir. Abrindo-se a uma perspectiva de uma ética preocupada 
com o futuro, esta nos ocuparia na prefiguração de uma situação-limite negativa para a terra e para as gerações futuras.

Segundo Jonas (apud MANCINI, 2000), “o malum imaginado deverá assumir o papel de malum experimentado e esta prefiguração não se apresenta por si só, mas deverá ser elaborada intencionalmente: a aquisição antecipada do pensamento dessa idéia torna-se, portanto, o primeiro dever, por assim dizer, propedêutico da nossa ética”.

O segundo dever precisa ser, segundo o autor, aquele de deixar influenciar-se por tal prefiguração, assumindo o medo da desventura como comportamento fisiológico e não como estado de ânimo patológico capaz de nos subjugar. Mesmo sabendo da nossa incapacidade de prever fatos a longo prazo, o temor por aquilo que poderia suceder sem torna, para Jonas, a fonte insubstituível da sabedoria. A heurística do medo deve ser a nova ética para guiar a humanidade, isto é, uma busca prudente das soluções mais adequadas que tutelem o homem e o mundo das escolhas irresponsáveis. A "substancial imperscrutabilidade humana, que sempre reserva surpresas, e a imprevisibilidade" são companheiras inseparáveis do processo tecnológico e científico. Essa incerteza, que poderia obstaculizar ou até mesmo paralisar a ação moral, deve transformar-se em preceito ético. Isso vale, principalmente, quando o que está em jogo é grande e os seus efeitos são irreversíveis, pois se trata de escolhas que interessam o futuro da humanidade e, mais em geral, a vida sobre a terra. Uma vez que ninguém tem o direito de pôr em risco a totalidade dos interesses dos outros, o desenvolvimento da tecnologia não pode colocar sob hipoteca a sobrevivência e integridade da humanidade. (MANCINI et al, 2000).

Para Jonas, a urgência histórica de recomeçar o controle dos efeitos das ações humanas induz o autor a subordinar qualquer responsabilidade ao agir responsável que é correlato e proporcionado ao poder. Precisamente porque, paradoxalmente, a única certeza nas mãos do homem é constituída pelo saber-se incapaz de prever os efeitos a longo prazo de seu poder desmedido, o futuro aparece para Jonas como a dimensão mais típica da responsabilidade ética. E, sendo que hoje, o futuro da vida corre o máximo risco, ele torna-se o objeto prioritário da consciência moral e da ação que dele provém. As únicas possibilidades de salvação, como se disse, vêm da escuta atenta das previsões de desventura. A pretensão de mudar o mundo deve ceder lugar ao dever de proteger a vida e de preservar o futuro. (MANCINI et al, 2000).

Hans Jonas afirma que "o homem nos é o único ser conhecido que pode ter responsabilidade. na medida em que ele a pode ter, ele a tem. A capacidade de responsabilidade significa já a colocação sob seu imperativo: o próprio poder leva consigo o dever" (...) “A capacidade de responsabilidade é uma capacidade ética, que repousa sobre a aptidão ontológica do homem de 
escolher entre alternativas de ação com saber e vontade. Responsabilidade é, portanto, complementar `a liberdade” (apud BARTHOLO JR. e BURSZTYN, 2001).

O filósofo alemão propõe uma ontologia teleológica que identifica a finalidade do ser com o dever-ser universal, do qual nasce uma norma obrigatória no plano moral. A finalidade imanente na natureza adquire a forma de um "sim à vida", que se renova em cada processo de autoconservação. $\mathrm{O}$ autor passa da ética subjetiva, em cujo horizonte contam apenas as escolhas humanas, a uma ética objetiva, onde a obrigação nasce "da exigência de um objeto e o vínculo está em confrontação com esse objeto". A situação paradigmática na qual temos experiência de tal vínculo objetivo, independentemente das nossas preferências, é a relação entre pais e filhos, definido por Jonas como o "arquétipo atemporal de toda responsabilidade", já que a evidencia do dever responder ao apelo da vida se tem na relação com o recém-nascido, "o qual num só respiro dirige incontestavelmente um 'deve' ao ambiente circundante, a fim de que tome conta dele". Como toda evidência, um tal apelo pode não ser atendido. Enquanto a natureza endereça os outros seres à tutela espontânea da própria conservação, no homem tudo isso se torna problemático por causa de seu poder-escolher, portanto, do fato de que, para ele, o "sim à vida" deve passar pela livre confirmação da vontade (MANCINI et al, 2000).

A natureza alberga valores, posto que abriga nela fins em si mesma, e, portanto, tudo pode ser considerado, menos uma natureza desprovida de valores. A pergunta é se é nosso dever ser solidários com os valores da natureza. O próprio Jonas responde: “A responsabilidade instituída pela natureza, ou seja, a que existe por natureza independe de nossa concordância prévia. É uma responsabilidade irrevogável, incancelável e global” (JONAS, 1995).

Para Jonas, o interesse do homem deve se identificar com o dos outros membros da natureza, pois ela é a nossa moradia comum. A preservação da natureza é a condição de sobrevivência do homem, e é no âmbito desse destino solitário que Jonas fala de dignidade própria da natureza. Há também uma responsabilidade de natureza metafísica do homem sobre o meio ambiente. "O homem converteu-se em perigo não só para sua própria existência como para toda a biosfera. Assim, a rica natureza está a nossa mercê e exige nossa proteção" (SIQUEIRA, 2005).

Kant dizia: Age de tal maneira que possas querer que tua ação se converta em lei universal'. Jonas propõe um novo imperativo, um novo paradigma para a ação humana, assim formulado: "age de tal maneira que os efeitos de tua ação não sejam, lesivos para a futura possibilidade de vida humana". Não é lícito arriscar nossas vidas e, de igual maneira, arriscar a vida da humanidade. O imperativo de Jonas reconhece o coletivo e contempla o futuro, enquanto o 
imperativo kantiano está dirigido ao indivíduo e seu critério é instantâneo. A responsabilidade de cada ser humano para consigo mesmo é indissociável da responsabilidade que se tem para com todos os homens. Trata-se de uma solidariedade que o liga a todos os homens e à natureza (SIQUEIRA, 2005).

A proposta de Hans Jonas é fundamentar uma modernidade ética apta a restringir a capacidade humana de agir como destruidor da auto-afirmação do ser, expressa na perenização da vida. Desde uma tal perspectiva, podemos conceber o desenvolvimento sustentável como uma proposta que tem em seu horizonte uma modernidade ética, não apenas uma modernidade técnica. Pois o princípio "sustentabilidade" implica incorporar ao horizonte da intervenção transformadora do "mundo da necessidade" o compromisso com a perenização da vida (BARTHOLO JR. e BURSZTYN, 2001).

O desenvolvimento sustentável exige assumir perspectivas de longo prazo, numa visão de futuro em que a incerteza e a surpresa se fazem presentes. A estratégia de ação deve ser sempre buscar uma razoável gama de opções para haver uma desejável flexibilidade de resposta (BARTHOLO JR. e BURSZTYN, 2001).

O princípio ético de Responsabilidade de Jonas guarda simetrias com o princípio de precaução do Direito Ambiental, expresso no Princípio 15 da Declaração do Rio de Janeiro, de 1992: “de modo a proteger o meio ambiente, o princípio da precaução deve ser amplamente observado pelos Estados, de acordo com suas capacidades. Quando uma ameaça de danos sérios ou irreversíveis, a ausência de absoluta certeza científica não deve ser utilizada como razão para postergar medidas eficazes e economicamente viáveis para prevenir a degradação ambiental (BRASIL, 1992).

Jonas, sem qualquer acento utópico, aponta para uma mudança substancial da práxis política. Ele dirige-se diretamente aos governantes e aos governos antes que aos indivíduos e aos povos. Aos governos cabe a tarefa de mediar a exigência do controle das conseqüências a curto prazo das opções políticas com a necessidade de ponderar as decisões, cujos efeitos são a longo prazo. (...) Jonas remete o senso de ser livres não à soberania do arbítrio, e sim ao vínculo de ser responsáveis (MANCINI et al, 2000).

Tem grande importância estratégica para o desenvolvimento sustentável a melhoria da comunicação entre a comunidade científica e tecnológica, os tomadores de decisões políticas e o público. Decisões em consonância com o princípio sustentabilidade são decisões éticas, que contribuem para a manutenção e aperfeiçoamento de sistemas de sustentação da vida (BARTHOLO JR. e BURSZTYN, 2001). 


\section{CONCLUSÃO: ÉTICA E SUSTENTABILIDADE}

Segundo Moran, "Eis a péssima notícia: estamos perdidos, irremediavelmente perdidos. Se há um evangelho, isto é, uma boa notícia, deve partir da ruim; estamos perdidos, mas temos um teto, uma casa, uma pátria: o pequeno planeta em que a vida criou o próprio jardim, em que os seres humanos formaram os seus lares, em que já a humanidade deve reconhecer a própria casa comum. Não é a Terra prometida, não é o paraíso terrestre. É a nossa pátria, o lugar da nossa comunidade de destino de vida e de morte terrenos. Devemos cultivar o nosso jardim terrestre, o que quer dizer civilizar a Terra. O evangelho dos homens perdidos e da Terra pátria nos diz: devemos ser irmãos, não porque seremos salvos, mas porque estamos perdidos" (apud MANCINI et al, 2000).

A lógica do desenvolvimento necessita ser subordinada aos imperativos de uma modernidade ética, não apenas uma modernidade técnica. E essa ética necessita dar resposta a novos desafios. Não se trata mais de encontrar termos relacionais equânimes para um "contrato social" firmado em condições de reciprocidade e simetria. Trata-se de enquadrar eticamente relações de poder assimétricas e, no limite, unilaterais e não recíprocas. Esse é notoriamente o caso da vulnerabilidade das condições futuras da vida com respeito a decisões e intervenções realizadas hoje na realidade. Outro aspecto decisivo é a necessidade de considerar o enquadramento ético de processos irreversíveis, ou seja, quando não nos é possível corrigir amanhã os efeitos indesejáveis de cursos de ação desencadeados hoje. A idéia tradicional de um "contrato" inter pares como fundamento da ética fracassa aqui. A sustentabilidade demanda uma nova concepção: um "pacto" entre desiguais e diversos, como se pode caracterizar de modo exemplar na dimensão temporal "futurista", ou seja, é preciso hoje assegurar a qualidade de vida das gerações futuras (BARTHOLO JR. e BURSZTYN, 2001).

A relação entre a ética e a sustentabilidade é dada pela própria necessidade de sobrevivência do homem. Diante do arsenal científico e tecnológico, dos níveis requeridos para a movimentação da economia mundial, preponderantemente pelo modo de produção capitalista, do uso e abuso dos recursos ambientais remanescentes, diante dos vaticínios dos pesquisadores quanto às alterações climáticas talvez irreversíveis, ainda que passíveis de improvável reversão, da possibilidade de escassez dos recursos vitais como a água potável, da incompetência ou omissão humana em extinguir a fome, a doença e a miséria, e diante da propensão do homem pela guerra, somente uma profunda mudança paradigmática nos pressupostos éticos das ações humanas podem configurar um convívio harmônico e estável entre os seres. 
A sustentabilidade necessita deixar de ser categoria acadêmica e contra-hegemônica na sociedade, passando a integrar os valores legítimos da prática da cidadania cosmopolita, global. O fundamento das ações mais comezinhas como o abrir e fechar de uma torneira devem estar impregnados não apenas de conhecimentos, mas principalmente, de compromissos éticos com os semelhantes, habitantes de um mesmo orbe. Este compromisso não se restringe ao presente, mas deve lançar luzes para o futuro, garantindo às futuras gerações o conhecimento do mundo tal qual hoje ele é conhecido.

Em Kant, o imperativo categórico, para a valorização da universalidade das ações, bem como da utilização dos seres e da natureza não somente como meio, mas como fins em si, donos de qualidades intrínsecas e únicas por serem ainda reconhecidas. Também em Kant, as condições para a paz, requisitos para a cidadania cosmopolita - pelo entendimento de que todos são mais que nunca cidadãos do mundo - bem como sua conseqüência inequívoca, a sustentabilidade.

O agir comunicativo de Habermas, ocupado com a justiça, mostrando a possibilidade de escolhas moralmente adequadas porque compartilhadas pelo interesse comum, como as questões climáticas evidenciam. Ainda em Habermas, a sua ética do discurso, onde todos têm a mesma possibilidade e legitimidade de participar do estabelecimento de normas que vinculem a todos. A sustentabilidade contempla os princípios da informação e o da participação, princípios do Direito Ambiental, afinados à ética do discurso.

E o princípio da Responsabilidade de Jonas, que pretende um agir cauteloso, apontando o descompasso entre a factibilidade da destruição, inclusive ambiental, e a consciência ética das conseqüências imprevisíveis dos atos praticados no presente. Apoiando-se na possibilidade de danos, preocupa-se em evitar que as possibilidades técnicas e práticas levem os homens irresponsavelmente além dos limites da viabilidade da vida. A sustentabilidade, acorde o princípio de responsabilidade, clama do homem por uma ação de tutela do meio ambiente, elemento vulnerável frente à capacidade de destruição desse mesmo homem.

Para Adela Cortina,

Evitar a destruição da ecosfera, afastar o risco de desertificação do planeta, exterminar a praga da fome e da guerra, destruir a maldição da pobreza, são tarefas que excedem em muito as possibilidades de uma nação. Vivemos - é inegável - em uma "Aldeia Global”, que tem deixado pouquíssimo aos estados-nação, e requer para seus problemas soluções globais. Diante de fatos irreversíveis como este, podem produzir-se ao menos três reações: a temerosa e catastrofista, receosa de fazer marcha para trás, assustada frente às mudanças a seu ver apocalípticos, situados muito acima de qualquer 
nível de intervenção humana; a oportunista, que no rio revolto do desconhecimento geral trata de desviar as águas para seu proveito individual ou grupal, que é enfim o que lhe importa; a ética, convencida de que as inovações devem converter-se em oportunidades de progresso para todos, e de que, para isso, teremos que "pegar o touro pelos chifres". "Pegar o touro pelos chifres" significa em nosso caso abandonar os discursos catastrofistas, acolher com otimismo o novo e orientá-lo para metas já tão antigas, porém ainda não trilhadas, como a realização de maior liberdade, igualdade e solidariedade. Para isso será necessário assumir globalmente os problemas que globalmente se apresentam, abandonando, por retrógrados, tanto o catastrofismo quanto o egoísmo oportunista (CORTINA, 1997; tradução nossa).

As contribuições das éticas de Kant, Habermas e Jonas podem auxiliar na identificação das variáveis implícitas em toda deliberação ética/moral, suportando decisões mais condizentes com os requisitos do desenvolvimento sustentável, permitindo assim a perpetuação da vida, em todas as suas surpreendentes dimensões e possibilidades.

\section{REFERÊNCIAS BIBLIOGRÁFICAS}

ALMEIDA, Fernando. O bom negócio da sustentabilidade. Rio de Janeiro, Nova Fronteira, 2002. 192p. ISBN 85-20912-66-4

CAMARGO, Sérgio Xavier de. A proposta kantiana de paz democrática: Um estudo sobre “À Paz Perpétua". 2006. 90p. Monografia (Especialização em Filosofia Moderna e Contemporânea: Aspectos Éticos e Políticos) - Universidade Estadual de Londrina, PR.

COMISSÃO MUNDIAL SOBRE MEIO AMBIENTE E DESENVOLVIMENTO: Nosso futuro comum. Rio de Janeiro; Fundação Getúlio Vargas, 1988.

CORTINA ORTZ, Adela. Ciudadanos del Mundo: Hasta uma teoria de la ciudadanía. Madrid: Ed. Alianza, 1997. Em Espanhol.

HABERMAS, Jurgen. Para o uso pragmático, ético e moral da razão prática. In: STEIN (Orgs), Dialética e liberdade. Petrópolis, Porto Alegre: Editora da Universidade federal do Rio Grande do Sul, 1993.

JONAS, Hans. El Principio de Responsabilidad: ensayo de uma ética para la civilización tecnológica. Barcelona, Herder, 1995. Em Espanhol.

KANT, Immanuel. Fundamentação da Metafísica dos Costumes. Lisboa: Edições 70, 2003, $119 \mathrm{p}$. 
KANT, Immauel. A paz perpétua e outros opúsculos. Lisboa: Ed. 70. 1995. Trad. Artur Morão.

MACHADO, Paulo Afono Leme. Princípios gerais do direito ambiental. In: Direito Ambiental Brasileiro. 10. ed. São Paulo: Malheiros, 2002.

MATEO, Ramón Martín. Manual de Derecho Ambiental. 3. ed. Cizur Menor (Navarra): Aranzadi, 2003. Em Espanhol.

PENTEADO, Hugo Ferraz. Economia e Meio Ambiente. Disponível em www.ibps.com.br. Acesso em: 19 jun. 2007.

SOSOE, Lukas K. Dever. In: CANTO-SPERBER, Monique (Org.) Dicionário de Ética e Filosofia Moral. Trad. Magda Lopes. São Leopoldo: Ed. Unisinos, 2003.

TUR, Antonio Aledo.; GÓMEZ, José Andrés Dominguez (orgs). Problemas sócio-ambientais II: as acoutopias. In: Sociología Ambiental. Granada: Grupo Editorial Universitário. 2002. p.462. Em Espanhol. 